\title{
Impact of intermittent fasting on body weight in overweight and obese individuals
}

\author{
(iD) Carlos Henrique Ribeiro Lima ${ }^{1}$ \\ (iD) lara Katrynne Fonsêca Oliveira' \\ (D) Karoline de Macêdo Gonçalves Frota ${ }^{1}$ \\ (iD) Cecilia Maria Resende Gonçalves de Carvalho' \\ (iD) Adriana de Azevedo Paiva' \\ (iD) Viriato Campelo ${ }^{2}$ \\ (iD) Maria do Carmo de Carvalho e Martins ${ }^{3}$
}

\begin{abstract}
1. Universidade Federal do Piauí, Departamento de Nutrição, programa de Pós-graduação em Alimentos e Nutrição. Campus Universitário Ministro Petrônio Portela, s/n -Bloco 13- Bairro Ininga, 64049-550, Teresina - PI, Brasil. 2. Universidade Federal do Piauí, Departamento de Parasitologia e Microbiologia, programa de Pós-graduação em Ciências e Saúde. Campus Universitário Ministro Petrônio Portela. Bairro Ininga, 64049-550, Teresina - PI, Brasil.

3. Universidade Federal do Piauí, Departamento de Biofísica e Fisiologia, Pós-graduação em Alimentos e Nutrição. Campus Universitário Ministro Petrônio Portela, s/n -Bloco 13- Bairro Ininga, 64049-550, Teresina - PI, Brasil.
\end{abstract}

http://dx.doi.org/10.1590/1806-9282.66.2.222

\section{SUMMARY}

OBJECTIVE: To verify the relationship of intermittent fasting in the bodyweight of overweight and obese individuals through a systematic literature review.

METHODS: This is a systematic review based on randomized controlled trials. The articles were consulted in the databases: Science Direct, PubMed e BVS. This review was evaluated through the PRISMA recommendation.

RESULTS: After the selection process, four articles were included in this review, comparing intermittent fasting (IF) with calorie restriction diet (CRD) as a control group. In 2 studies using similar protocols, there was no significant reduction in body weight of overweight or obese subjects. In the other two studies using different protocols, weight loss was significant in the IF group compared to the CRD group. CONCLUSIONS: Results did not provide evidence of the effect of intermittent fasting on weight loss in overweight or obese individuals. KEYWORDS: Fasting. Body Weight. Overweight. Obesity.

\section{INTRODUCTION}

Intermittent fasting (IF) is a dietary practice in which periods of regular consumption of foods and beverages are interspersed with periods of severe energy restriction or by fasting, typically in 1 to 3 days per week. The objective of fasting is to reduce the total energy value, thus creating a negative energy balance, which results in weight loss. ${ }^{1}$

The excessive intake of energy is associated with the worldwide increase in the incidence of chronic diseases, including obesity, type II diabetes mellitus 
(DM type II), and metabolic syndrome. Caloric restriction by intermittent fasting increases longevity and reduces the incidence of chronic non-communicable diseases associated with aging, such as obesity, cardiovascular diseases, cancer, renal disease, and diabetes mellitus. ${ }^{1.2}$

Fasting is associated with substantial weight loss in short periods of time, around 8 to 12 weeks, accompanied by the control of dyslipidemia, arterial pressure, and changes in body composition..$^{3-5}$ In addition, increases in insulin sensitivity have also been demonstrated as impacts of intermittent fasting practice. ${ }^{4.5}$

As stated above, the dietary practice of using intermittent fasting has an impact on the bodyweight of overweight or obese individuals, as well as in reducing the risk of health problems. Therefore, the objective of this study was to verify the relationship of intermittent fasting on the bodyweight of overweight and obese individuals through a systematic review of the literature.

\section{METHODS}

We performed a systematic review of randomized clinical trials based on the recommendations of PRISMA (Preferred Reporting Items for Systematic reviews and Meta-Analyses) ${ }^{6}$

We used the PICO strategy to draw up the main question of the present study, which culminated with the delimitation of the following: Does intermittent fasting have any effect on bodyweight in overweight or obese individuals? Each PICO dimension was equivalent to the following elements: $(\mathrm{P})$ overweight or obese individuals, (I) Intermittent Fasting, (C) calorie-restricted diet, and $(\mathrm{O})$ changes in bodyweight of overweight or obese individuals.

The online search was performed in the PubMed, Science Direct, and Virtual Health Library (VHL) databases, from July to August of 2019, by two authors independently (C.H.R.L and I.K.F.). The connective "and" was used in combination with the Medical Subject Headings (MeSH terms): "Fasting”. "Body Weight", "Overweight”, and "Obesity”. With their respective analogs in Portuguese and Spanish.

The search for articles in the different databases was performed with the following combinations of descriptors: SEARCH 1: Body composition AND Fasting OR fasting intermittent; SEARCH 2: Obesity OR Adiposity AND Overweight AND Fastin intermittent.
The same search combinations were used in Spanish and Portuguese.

The clinical trials searched had a limits of publication date between 2015 and 2019, and had to have been published in English, Portuguese, or Spanish, involving overweight or obese individuals, without restriction of gender, ethnicity, and age over 18 years, available in its entirety, and including intermittent fasting as a dietary practice.

Were excluded studies that included pregnant women, heart disease, publications whose full text was inaccessible, chapters of books, manuals, congress publications, theses, dissertations, articles, reviews, articles outside of the databases, and in vitro studies involving animals. The details of the selection of articles are described in Figure 1.

After defining the inclusion and exclusion criteria, the articles were read and analyzed by two authors independently (C.H.R.L and I.K.F.), initially by reading the title, then the title and abstract, and finally, the full text. In the event of a discrepancy between the evaluators, a third researcher was consulted.

The data extracted from the studies included: author, year of publication, location, sample size, variables analyzed, interventions, and outcomes.

To ensure the methodological quality of this review, we used the Jadad scale, ${ }^{7}$ employed by two authors independently for qualitative classification.

FIGURE 1. FLOWCHART OF THE IDENTIFICATION, ELIGIBILITY, AND SELECTION OF THE PAPERS INCLUDED IN THE SYSTEMATIC REVIEW.

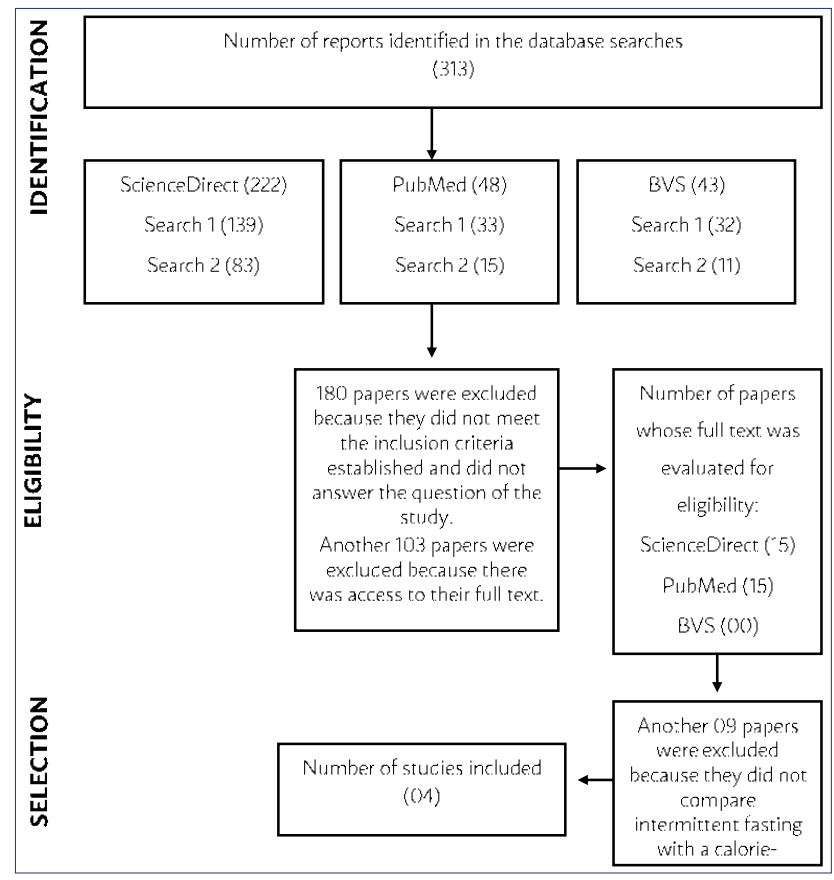


Scores were assigned to the studies (0-5) based on the following criteria: method of randomization, use of blinding, and description of the proportion of losses during follow-up.

\section{RESULTS}

We found 313 articles in the databases searched: ScienceDirect (222), PubMed (48), and BVS (43). After the screening process, 04 articles were considered eligible. The articles included in the last stage of selection were a consensus among researchers. Figure 1 shows the characteristics of the articles included.

The studies were conducted in overweight or obese individuals of both sexes and different locations. All studies used intermittent fasting (IF) as the intervention in comparison with a calorie-restrictive diet (CRD) in the control group. As to the duration of the intervention using intermittent fasting, it ranged from 08 weeks to 04 months.

The papers met most of the criteria established by the tool for evaluation of the methodological quality of randomized clinical trials proposed by Jadad et al. ${ }^{7}$ with a score of 3 in all 4 papers, which indicates that the studies had a reliable methodological quality reliable that could be extrapolated to other research scenarios (Table 1).

Table 2 shows the results of four studies that used randomized clinical trials to evaluate the effect of intermittent fasting on the bodyweight of overweight or obese individuals, using different times of fasting and intervention duration.

Trepanowski et al. ${ }^{8}$ conducted a study in Chicago with obese individuals for 24 weeks to compare strategies between the IF and CRD groups. In this protocol, they used fasting for 24 hours on alternate days, in which period of fasting, in the IF group, energy consumption was only $25 \%$, while in the CRD group, it was $75 \%$.

The results of this intervention did not demonstrate significant differences in bodyweight loss, drawing attention to the figures of such reduction $(-7.7 \mathrm{~kg}$ \pm 1.0 ) in both groups after the intervention with fasting.

Corroborating the previous study, a survey carried out in the Colorado region, USA, by Catenacci et al. ${ }^{9}$ also revealed no significant effect of fasting on the bodyweight of overweight or obese individuals in the IF group $(-8.2 \pm 0.9 \mathrm{~kg})$, when compared to the CRD in this same population $(-7.1 \mathrm{~kg} \pm 1.0)$.

The protocol used consisted in providing a diet with a calorie deficit of $400 \mathrm{kcal} /$ day, based on the estimated energy needs of the participants included in the CRD group, whereas for the participants of the IF group the protocol was fasting with total calorie restriction for 24 hours on alternate days.

Two studies assessed the effect of intermittent fasting in overweight or obese individuals comparing IF groups with CRD groups, using different protocols. In both studies, the weight reduction was significant in the IF group in comparison to the CRD group. ${ }^{10.11}$

In the first study, the protocol consisted of a calorie restriction of $500 \mathrm{kcal} /$ day based on the energy needs in the CRD and IF groups; participants in the IF group were instructed to fast for 18 hours/day for the 24 weeks of intervention. In addition, the participants of the IF group had two meals per day only, while the ones in the CRD group had their six meals regularly. The findings of this research have demonstrated a reduction in bodyweight of $-4,0 \mathrm{~kg} \pm 1.0$ in the IF group in comparison with $-2,0 \mathrm{~kg} \pm 1.0$ in the CRD group. ${ }^{10}$

In the second study, the protocol was carried out in participants of both sexes, according to the Buchinger method, which consists of fasting from solid foods for 7 consecutive days in the IF group and a balanced diet in the CRD group. In this protocol, the intervention lasted for 4 months. The outcomes of this research revealed a significant impact on weight reduction in the IF group $(-3.5 \pm 4.5)$ in comparison to the CRD group $(-2.0 \pm 4.8) .{ }^{11}$

\section{DISCUSSION}

The main difference between the calorie-restrictive diet protocols and the frequency of fasting involves schemes with restriction of calories without the need to eliminate one or more meals during the day. In contrast, intermittent fasting requires deprivation of food on alternate days during the week. ${ }^{12}$

The results of this revision corroborate other studies that evaluated the loss of bodyweight using intermittent fasting as a strategy. The authors showed that the loss varies from 2.5 to $9.9 \%$, including the loss of associated body fat. These results are consequences of metabolic changes caused by fasting, which lead to an increase in lipolysis, proteolysis, and the depletion of glycogenolysis. ${ }^{13}$

According to Azevedo et al. ${ }^{14}$ the metabolic alterations are observed soon after the beginning of the fasting period. Plasma glucose levels fall and remain low during this period; lipolysis, ketogenesis, and gluconeogenesis increase while glycogenolysis decreases. 
TABLE 1. PAPERS RELATED TO THE IMPACT OF VITAMIN D IN THE GLUCOSE PROFILE OF PRE-DIABETIC INDIVIDUALS: CHARACTERISTICS OF THE STUDIES INCLUDED IN THE SYSTEMATIC REVIEW.

\begin{tabular}{|c|c|c|c|c|c|c|c|c|}
\hline \multirow{2}{*}{$\begin{array}{l}\text { Authors/Year of } \\
\text { publication }\end{array}$} & \multirow{2}{*}{$\begin{array}{l}\text { Location of the } \\
\text { Study }\end{array}$} & \multirow{2}{*}{$\begin{array}{l}\text { Partic. } \\
\text { CRD/IF }\end{array}$} & \multirow{2}{*}{ Sex } & \multirow{2}{*}{$\begin{array}{l}\text { Age } \\
\text { (years) }\end{array}$} & \multicolumn{2}{|c|}{ Intervention } & \multirow{2}{*}{ Variable } & \multirow{2}{*}{ Outcomes } \\
\hline & & & & & Fasting & Duration & & \\
\hline $\begin{array}{l}\text { Trepanowski et al., } \\
2017 .\end{array}$ & Chicago & $34 / 35$ & $M / F$ & $18-65$ & 24 hours & 24 weeks & Bodyweight (kg) & $\begin{array}{l}\text { No significant reduction } \\
\text { in bodyweight was found. }\end{array}$ \\
\hline $\begin{array}{l}\text { Catenacci et al., } \\
2016 .\end{array}$ & Colorado & $14 / 15$ & $M / F$ & $18-55$ & 24 hours & O8 weeks & Bodyweight (kg) & $\begin{array}{l}\text { No significant reduction } \\
\text { in bodyweight was found } \\
\text { in this study. }\end{array}$ \\
\hline $\begin{array}{l}\text { Kahleova et al., } \\
2014\end{array}$ & Czech Republic & $27 / 27$ & $M / F$ & $30-70$ & 18 hours & 24 weeks & Bodyweight (kg) & $\begin{array}{l}\text { Intermittent fasting has } \\
\text { a significant effect on the } \\
\text { loss in bodyweight. }\end{array}$ \\
\hline $\begin{array}{l}\text { Chenying et al., } \\
2017\end{array}$ & Berlin & $23 / 23$ & $M / F$ & $25-75$ & 168 hours & 4 months & Bodyweight (kg) & $\begin{array}{l}\text { The study revealed } \\
\text { significant bodyweight } \\
\text { loss using intermittent } \\
\text { fasting. }\end{array}$ \\
\hline
\end{tabular}

M- Male. F - Female. Kg - kilogram.

TABLE 2. DISTRIBUTION OF STUDIES INCLUDED IN THE REVIEW ACCORDING TO THE METHODOLOGICAL QUALITY OF THE RANDOMIZED CLINICAL TRIALS, PER JADAD ET AL.

\begin{tabular}{l|l|l|l}
\hline Items & E1 & E2 & E3 \\
\hline Was the study described as randomized? & Yes & Yes & Yes \\
\hline Was the study described as double-blind? & No & No & Yes \\
\hline Was there a description of exclusions and losses? & Yes & Yes & Yes \\
\hline Was the randomization method described and appropriate? & Yes & Yes & No \\
\hline Was the double-blind method described and appropriate? & No & Yes & Yes \\
\hline Points & 3 & No & 3 \\
\hline
\end{tabular}

E - Study. E1 - Trepanowski et al..$^{8}$ E2 - Catenacci et al.9; E3 - Kahleova et al. ${ }^{10}$; E4 - Chenying et al.1․

The increase in lipolysis and fat oxidation provides the substrate for gluconeogenesis and compensates for the decline in carbohydrate oxidation and glycogenolysis. This process also causes a moderate increase in proteolysis and protein oxidation.

Intermittent Fasting also negatively regulates the expression in muscle tissue of mTOR, the gene responsible for modulating nutritional signaling, which decreases protein synthesis and increases the expression of carnitine palmitoyltransferase I (CPT-1) in muscle tissue, as well as lipid oxidation. ${ }^{14}$

These metabolic processes lead to weight loss, as demonstrated by the results of two studies included in this review, but it is worth noting that these studies followed different protocols; the other two studies included had similar protocols showed no significant results.

Varady et al. ${ }^{4}$ supports intermittent fasting as an efficient dietary practice that can culminate in health benefits. This conclusion is based on their study on 16 obese individuals submitted to eight weeks of intermittent fasting, consuming $25 \%$ of their basal energy needs. The fasting protocol promoted significant weight loss, reduced adipose tissue mass, blood pressure, and heart rate, improved the lipid profile, reduced the total cholesterol and LDL-c, and increased the levels of HDL cholesterol.

This metabolic regulation, according to Santos and Macedo $^{15}$, can increase the liver production of apolipoprotein A (apo A) and decrease apolipoprotein B (apo $B)$. The production of apo A increases HDL-c since it is its precursor. The increased expression of PPARa is also responsible for the increase in serum HDL. The reduced production of apo $\mathrm{B}$ also promotes a decrease in serum levels of VLDL, LDL, and small and dense LDL (sdLDL).

The limitations of this review are related to the profile of the articles included, considering they used different protocols, different ages, and different genres. Another limitation is regarding the sample size of the studies, which were restricted.

The strengths are related to the information that although intermittent fasting is disseminated among the general population as an effective dietary practice for weight loss, randomized clinical trial studies comparing IF are not conclusive in demonstrating better effects for weight loss in relation to calorie-restrictive diets. 


\section{CONCLUSION}

The results of this systematic review did not provide conclusive evidence of greater benefits from intermittent fasting on the bodyweight of overweight or obese individuals when compared with a diet of calorie restriction in different periods of intervention. Therefore, further interventional studies on intermittent fasting are needed with larger sample sizes and standardization of protocols.

\section{Author's contributions}

The authors Carlos Henrique Ribeiro Lima and Iara Katrynne Fonsêca Oliveira contributed to the writing of the text of the article; the other co-authors contributed to the evaluation and revision of the article.

\section{RESUMO}

OBJETIVO: Verificar a relação do jejum intermitente no peso corporal de indivíduos com sobrepeso e obesidade por meio de uma revisão sistemática da literatura.

MÉTODOS: Trata-se de uma revisão sistemática, baseada em ensaios clínicos randomizados. Os artigos foram consultados nas bases de dados: Science Direct, PubMed e BVS. A avaliação dessa revisão ocorreu por meio da recomendação Prisma.

RESULTADOS: Após o processo de seleção, quatro artigos foram incluídos nesta revisão, comparando o jejum intermitente (JI) com dieta de restrição calórica (DRC) como grupo controle. Em dois estudos com utilização de protocolos semelhantes não houve redução significativa no peso corporal dos indivíduos com sobrepeso ou obesidade. Já nos outros dois estudos com utilização de protocolos distintos, a perda de peso foi significativa no grupo Jl em comparação ao grupo DRC.

CONCLUSÕES: Os achados desta revisão não fornecem evidências plausíveis do efeito do jejum intermitente na perda de peso em indivíduos com sobrepeso ou obesidade.

PALAVRAS-CHAVE: Jejum. Peso corporal. Sobrepeso. Obesidade.

\section{REFERENCES}

1. Hill JO, Wyatt HR, Peters JC. Energy balance and obesity. Circulation. 2012;126(1):126-32

2. Harvie NM, Pegington M, Mattson MP, Frystyk J, Dillon B, Evans G, et al. The effects of intermittent or continuous energy restriction on weight loss and metabolic disease risk markers: a randomized trial in young overweight women. Int J Obes (Lond). 2011;35(5):714-27.

3. Varady KA. Intermittent versus daily calorie restriction: which diet regimen is more effective for weight loss? Obes Rev. 2011;12(7):e593-601.

4. Varady KA, Bhutani S, Church EC, Klempel MC. Short-term modified alternate-day fasting: a novel dietary strategy for weight loss and cardioprotection in obese adults. Am J Clin Nutr. 2009;90(5):1138-43.

5. Varady KA, Hellerstein MK. Alternate-day fasting and chronic disease prevention: a review of human and animal trials. Am J Clin Nutr. 2007;86(1):7-13.

6. Galvão TF, Pansani TSA, Harrad D. Principais itens para relatar Revisões sistemáticas e meta-análises: a recomendação PRISMA. Epidemiol SerV Saúde. 2015;24(2):335-42

7. Jadad AR, Moore RA, Carroll D, Jenkinson C, Reynolds DJ, Gavaghan DJ. Assessing the quality of reports of randomized clinical trials: is blinding necessary? Control Clin Trials. 1996;17(1):1-12.

8. Trepanowski JF, Kroeger CM, Barnosky A, Klempel M, Bhutani S, Hoddy $\mathrm{KK}$, et al. Effects of alternate-day fasting or daily calorie restriction on body composition, fat distribution, and circulating adipokines: secondary analysis of a randomized controlled trial. Clin Nutr. 2018;37(6 Pt A):1871-8.
9. Catenacci VA, Pan Z, Ostendorf D, Brannon S, Gozansky WS, Mattson MP et al. A randomized pilot study comparing zero-calorie alternate-day fasting to daily caloric restriction in adults with obesity. Obesity (Silver Spring). 2016;24(9):1874-83.

10. Kahleova H, Belinova L, Malinska H, Oliyarnyk O, Trnovska J, Skop V, et al. Eating two larger meals a day (breakfast and lunch) is more effective than six smaller meals in a reduced-energy regimen for patients with type 2 diabetes: a randomised crossover study. Diabetologia. 2014;57(8):1552-60.

11. Li C, Sadraie B, Steckhan N, Kessler C, Stange R, Jeitler M, et al. Effects of a one-week fasting therapy in patients with type-2 diabetes mellitus and metabolic syndrome: a randomized controlled explorative study. Exp Clin Endocrinol Diabetes. 2017;125(9):618-24.

12. Rothschild J, Hoddy KK, Jambazian P, Varady KA. Time-restricted feeding and risk of metabolic disease: a review of human and animal studies. Nutr Rev. 2014;72(5):308-18.

13. Stockman MC, Thomas D, Burke J, Apovian CM. Intermittent fasting: is the wait worth the weight? Curr Obes Rep. 2018;7(2):172-85.

14. Azevedo FR, Ikeoka D, Caramelli B. Effects of intermittent fasting on metabolism in men. Rev Assoc Med Bras. 2013;59(2):167-73.

15. Santos HO, Macedo RCO. Impact of intermittent fasting on the lipid profile: Assessment associated with diet and weight loss. Clin Nutr ESPEN. 2018;24:14-21. 